\title{
Argumentação em Livros Didáticos de Matemática: \\ Brasil e Canadá
}

\author{
Argumentation in Math Teaching Books: \\ Brazil and Canada
}

\author{
João Paulo Attie ${ }^{1}$ \\ Cathy Marks Krpan ${ }^{2}$
}

Submetido em 21 de junho e aprovado em 29 de agosto de 2020.

Resumo: Tendo como panorama a diferença apontada entre dois países, Brasil e Canadá, em relação à aprendizagem em matemática, conforme dados do Programa Internacional de Avaliação de Alunos, PISA, este artigo busca apresentar semelhanças e diferenças nos processos de argumentação no ensino da disciplina, relacionados aos principais livros didáticos adotados nas duas regiões. A partir de uma pesquisa sobre os sistemas educacionais dos dois países, as coleções escolhidas para análise foram as recomendadas pelo Plano Nacional do Livro Didático, PNLD (National Textbook Plan), no Brasil e pela Trillium List, no Canadá. Nos fundamentamos nas categorias de argumentação esboçadas inicialmente por Balacheff (1988), e depois descritas por Attie (2016), a argumentação explicativa e a argumentação justificativa e consideramos adequado proceder à análise de conteúdo (Bardin, 2010) para a obtenção do nosso objetivo. Como resultados, pudemos perceber claramente como, em geral, os livros canadenses possuem uma maior preocupação em incentivar alguns aspectos como a autonomia e a busca de padrões, por exemplo, mas, apesar de uma diferença relevante na abordagem, ao analisarmos mais profundamente o enfoque no ensino dos conteúdos, em alguns casos, aparecem em algumas coleções canadenses, assim como na quase totalidade dos livros brasileiros, o que consideramos um apego excessivo às regras, em detrimento da exposição do processo envolvido no desenvolvimento das mesmas.

Palavras-Chave: Argumentação. Ensino de Matemática. Brasil-Canadá. Livro Didático.

Abstract: Considering the difference between two countries, Brazil and Canada, regarding mathematics learning, according to data from the International Student Assessment Program, PISA, this article presents some similarities and some differences in the argumentation processes in the teaching of the subject, related to the main textbooks adopted in both lands. Based on an investigation about the educational systems of the two countries, the collections chosen for analysis were those recommended by the National Textbook Plan (Plano Nacional do Livro Didático, PNLD), in Brazil and by Trillium List, in Canada. We base ourselves on the categories of argument initially sketched by Balacheff (1988) and later described by Attie (2016), explanative argumentation and justificative argumentation, and we consider it appropriate to proceed with the content analysis (Bardin, 2010) to obtain our objective. As a result of the research, we could clearly see how, in general, Canadian books have a greater concern to encourage some 
aspects such as autonomy and the search for standards, for example, but, despite a relevant difference in approach, when we analyze more deeply the focus on teaching contents, in some cases, appear in some Canadian collections, as well as in almost all Brazilian books, which we consider excessive adherence to the rules, rather than exposing the process involved in their development.

Keywords: Argumentation. Mathematics Teaching. Brazil-Canada. Textbook.

\section{Introdução}

Nos últimos sistemas de ranqueamento internacionais, em relação à aprendizagem de matemática, Brasil e Canadá são países que se encontram colocados em posições muito diferentes. Em um dos últimos PISA - Programa Internacional de Avaliação de Alunos, da $\mathrm{OCDE}^{3}$ (Organização para Cooperação e Desenvolvimento Econômico) relacionados à área, que ocorreu no ano de 2015, enquanto o Canadá, entre setenta países testados, figura entre os dez primeiros da lista, ao Brasil é relegado o sexagésimo quarto lugar. Essa avaliação é o maior estudo internacional de desempenho escolar da atualidade.

Entre as várias diferenças, econômicas, culturais, sociais e geográficas que podem ser apontadas entre os dois países, como causas para essa diferença de posição, partimos da hipótese que alguns aspectos do ensino de matemática poderiam estar entre esses fatores. A partir dessa suposição, escolhemos investigar, nesta pesquisa, os processos de argumentação presentes no ensino de matemática nos dois países. Evidentemente, fizemos uma opção por duas regiões, Sergipe e Ontario, uma no Brasil e outra no Canadá, respectivamente, e, a partir de exemplos nos livros adotados em cada uma dessas regiões, identificamos semelhanças e diferenças, em relação aos processos de argumentação adotados para alguns conteúdos de matemática escolhidos.

Uma das opções que tivemos que fazer foi em relação aos conteúdos de matemática a serem analisados. Tendo em vista nossa história docente e o fato de que defendemos um ensino de matemática em que a argumentação possua um papel relevante e que possa levar o indivíduo a uma formação crítica e consciente, optamos por alguns dos temas que são frequentemente considerados obstáculos dentro dos processos de ensino e de 
aprendizagem, por serem mais “delicados"4 em relação às suas demonstrações ou causas, quando vistos em sala de aula. Dito de maneira mais simples, escolhemos temas cujas respostas ao questionamento "por que ocorre dessa maneira?" nem sempre são as mais satisfatórias, do ponto de vista lógico e/ou didático. Os conteúdos matemáticos escolhidos para análise foram, assim, os critérios de divisibilidade, as expressões numéricas, a divisão de frações, as operações entre inteiros e o cálculo de áreas.

À primeira vista, pudemos perceber claramente como, em geral, os livros canadenses, em relação aos brasileiros, possuem uma maior preocupação em incentivar alguns aspectos, como a busca de padrões, o cálculo mental e as estimativas, confirmando o que apontam Lima et al (2012) e também Souza (2019). Apesar dessa diferença relevante na abordagem, ao analisarmos mais profundamente o enfoque no ensino dos conteúdos, em alguns casos, aparecem em algumas coleções canadenses, assim como na quase totalidade dos livros brasileiros, o que consideramos um apego excessivo às regras, em detrimento da exposição do processo envolvido no desenvolvimento das mesmas.

A pesquisa teve como uma relevante base de consultas os trabalhos já publicados a respeito da argumentação em materiais didáticos de Matemática, especialmente os de Sales e Pais (2008) e de Scheffer (2012), que discutem como se dá a presença da argumentação em livros didáticos e com a presença de novas ferramentas tecnológicas e, especialmente, em relação aos conteúdos de matemática nos materiais didáticos, aos trabalhos de Carvalho et al (2016), Cruz et al (2017) e Nascimento et al (2019), entre outros que investigaram a presença das categorias de argumentação nos livros de Matemática.

\section{1 - Sistemas de Ensino e de Formação}

No Brasil existe um órgão central, subordinado ao governo federal, o Ministério da Educação, que monitora, fiscaliza e delimita currículos e competências em relação ao sistema de ensino. No Canadá, ao contrário, essa gestão é extremamente descentralizada, com cada província legislando e estabelecendo seus próprios currículos e competências, com quase nenhuma interferência do governo nacional. A OCDE, em um documento recente, afirma que o sucesso do país no desempenho do PISA (em todas as províncias) 
acontece apesar de um papel do governo federal "de limitado a inexistente" (OCDE, 2010, p. 77).

Neste artigo, ao nos referirmos ao ensino canadense, estaremos tratando da legislação relativa apenas à província de Ontario, já que a organização das divisões de ensino no Canadá pode variar de província para província. De qualquer forma, em se tratando do tempo destinado à educação básica e aos conteúdos de matemática, não há diferenças tão significativas a ponto de não podermos estender os resultados a todo o Canadá.

Em que pese essa grande diferença na gestão dos sistemas de ensino, há alguma semelhança na maneira como são divididos os níveis de ensino nas regiões em que desenvolvemos nossa pesquisa. No Brasil, há quatro níveis de ensino obrigatórios, chamados de Educação Infantil (4 e 5 anos de idade), Ensino Fundamental I (anos iniciais), com duração de cinco anos, em uma faixa etária de 6 a 9 anos de idade, um segundo nível, que dura quatro anos e ocorre na fase conhecida como pré-adolescência, e que é chamado de Ensino Fundamental II (anos finais) e, finalizando a etapa da Educação Básica, o Ensino Médio, com duração de três anos. Na província de Ontario, de forma diversa, há quatro níveis na Educação Básica, três divisões no que é chamado de Ensino Elementar - a Divisão Primária, que vai dos 4 aos 9 anos, a Divisão Júnior, que dura três anos e compreende uma faixa dos 9 aos 12 anos e a Divisão Intermediária, dos 12 aos 14 anos. Por fim, há a Divisão Secundária, que dura quatro anos, dos 15 aos 18.

Nos dois países, a primeira fase conta, em geral, com um professor único para cada turma, que pode ser chamado de generalista e tem competência para lecionar conteúdos de matemática, da linguagem, das ciências sociais e das ciências.

Eventualmente, em ambos os casos, a escola conta com professores específicos para disciplinas como música, educação física, artes etc. Na segunda etapa, em geral, no Brasil, para alunos de 10 a 14 anos, as escolas contam com professores especialistas em disciplinas como matemática, ciências e linguagem. Esse arranjo existe em Ontário, e sua abrangência depende do orçamento do distrito escolar e dos administradores da escola, quer decidam ter professores especialistas ou não, e, neste último caso, as turmas continuam com um professor único para cada uma delas. 
O último nível se caracteriza como uma preparação para a fase adulta, seja com um caráter pré universitário, seja em um aspecto profissionalizante. Ainda pode existir nesta etapa - a terceira no Brasil e a quarta em Ontario - além do nível regular, escolas preparatórias para a vida profissional.

Quadro comparativo das grades na Educação Básica

\begin{tabular}{|c|c|c|c|}
\hline Idade & Brasil & Idade & Canadá (Ontario) \\
\hline \multirow{2}{*}{6 a 10 anos } & \multirow{2}{*}{ Ensino Fundamental I } & 4 a 9 anos & Primary Division \\
\hline & & 9 a 12 anos & Junior Division \\
\hline 10 a 14 anos & Ensino Fundamental II & 12 a 14 anos & Intermediate Division \\
\hline 15 a 17 anos & Ensino Médio & 15 a 18 anos & High School \\
\hline
\end{tabular}

Em relação ao exercício da docência, há diferenças fundamentais em relação à mínima formação inicial exigida nos dois países.

No Brasil, para poder exercer a profissão no Ensino Fundamental I, o indivíduo precisa de um curso de graduação, como Licenciatura em Pedagogia ou Normal Superior. Essa formação dura, normalmente, quatro anos. Já para o exercício da docência nos níveis do Ensino Fundamental II e Ensino Médio, há a necessidade de uma Licenciatura específica na matéria a ser lecionada (Matemática, Química, Letras etc.) e o profissional formado tem a habilitação para dar aulas somente dessa disciplina particular em qualquer um dos dois níveis.

No Canadá a formação exigida para a docência, em qualquer um dos níveis, é maior, em quantidade e qualidade. Além de um curso de graduação, há a necessidade de uma pós-graduação específica para lecionar, chamada geralmente de Teachers College. Nesse curso, o estudante vai se habilitar para a docência em um dos quatro níveis apenas. 
Quadro comparativo da formação inicial

\begin{tabular}{|l|l|l|}
\hline \multirow{4}{*}{$\begin{array}{l}\text { Formação } \\
\text { Inicial }\end{array}$} & Brasil & Canadá \\
\cline { 2 - 3 } & $\begin{array}{l}\text { Fundamental I: Pedagogia ou Normal } \\
\text { Superior (4 anos), e o graduado possui } \\
\text { licença para ensinar apenas neste nível } \\
\text { de Ensino. }\end{array}$ & $\begin{array}{l}\text { A Formação inicial compreende, } \\
\text { além de uma graduação, seguir } \\
\text { um curso de pós graduação para }\end{array}$ \\
\cline { 2 - 3 } & $\begin{array}{l}\text { Fundamental II e Médio: Licenciatura } \\
\text { em Matemática (4 anos), e o graduado } \\
\text { possui licença para ensinar matemática } \\
\text { em qualquer um dos dois níveis de } \\
\text { Ensino. }\end{array}$ & $\begin{array}{l}\text { que dá ao graduado a licença } \\
\text { para lecionar em um dos níveis } \\
\text { apenas. }\end{array}$ \\
\hline
\end{tabular}

\section{2 - Livros Adotados}

Para a escolha dos livros nesta pesquisa, buscamos analisar os livros mais utilizados em cada uma das regiões. No caso brasileiro, todos os livros analisados foram recomendados em Guias do Programa Nacional do Livro Didático e, em cada conteúdo, foram verificadas apenas as coleções da série relativa a ele. O Programa Nacional do Livro Didático - PNLD, configura-se como uma política pública que sofreu diversas mudanças desde que algo semelhante começou a ser implementado no país, em 1929, e que, atualmente, é responsável pela escolha e distribuição gratuita dos livros escolhidos a todas as escolas públicas do país. Para cada série, há uma indicação de cerca de uma dezena de livros, dos quais verificamos uma parcela respectiva a cada conteúdo analisado. No caso da presente pesquisa, obtivemos informações sobre os livros mais utilizados em Sergipe a partir de autores como Carvalho et al (2016) e Santos et al (2018) e buscamos os dados relativos aos conteúdos em dezenove livros $^{5}$, listados nas Referências Bibliográficas.

Em relação ao Canadá, a quantidade de coleções analisadas foi bem menor, devido ao fato de que, atualmente, existem duas versões de livros didáticos para matemática uma para Ontário e outra para as províncias do Oeste. Mais especificamente em relação à província de Ontario, as coleções fazem parte da Trillium List ${ }^{6}$, que contém a lista de todos os livros didáticos aprovados para uso na província. Neste caso, informações obtidas junto à maior instituição da província ligada à educação, a Universidade de Toronto, ratificaram nossa escolha, apontando para a existência de apenas duas companhias editando livros 
didáticos, com três coleções principais, das quais analisamos seis livros, também listados nas Referências Bibliográficas. Em termos de mercado, as editoras geralmente esperam que o novo currículo atualizado em Ontário seja lançado antes de escrever novos livros, já que o mercado de Ontário é o maior do Canadá.

Anteriormente, havia um currículo para as províncias do Oeste, de acordo com o Protocolo Canadense Norte e Oeste, Western and Northen Canadian Protocol, WNCP (CANADA, 2015) e outro para os territórios (que é o contexto para os livros utilizados neste estudo). Atualmente, encontra-se em processo uma uniformização deste currículo. Deve-se notar que o currículo de matemática em Ontário, à época deste estudo, não tinha sido atualizado desde 2007. Um novo currículo atualizado para Ontário pode estar pronto em breve e as editoras aguardam por essas normas para atualizarem as coleções. Enquanto isso não acontece, o Ministério da Educação de Ontário fornece recursos atualizados para os professores usarem, se desejarem suplementar o currículo.

Todos os conteúdos analisados são ensinados atualmente durante o período chamado de Ensino Fundamental II, no Brasil, e de Junior Division e Intermediate Division, no Canadá.

Em relação aos livros analisados, ratificamos que o principal critério de escolha foi o fato de estarem incluídos nas recomendações do PNLD, no caso brasileiro e da Lista Trillium, no caso canadense.

\section{3 - Argumentação}

A partir da perspectiva de vários autores e de nossa experiência em sala de aula, logramos definir duas categorias de argumentação principais que podem estar presentes em livros didáticos, a partir das diferenças existentes entre os conceitos de explicação e de justificação, desde a perspectiva de Balacheff (1988). Para o autor, enquanto a explicação supõe um discurso com o objetivo de tornar inteligível uma proposição ou um resultado, o termo justificativa compreende uma exposição das razões que os legitimam. A partir dessa concepção, Attie (2016), aponta duas categorias de argumentação presentes no ensino de matemática, que denomina de "argumentação explicativa" e de "argumentação justificativa”. No processo de ensino, a argumentação explicativa é utilizada quando se 
tenta convencer o aluno ao mostrar "como" se resolvem os problemas e questões da matemática. Desta forma, essa categoria de argumentação está imbricada ao uso de fórmulas e técnicas, quando o professor apresenta o conteúdo sem contextualizações históricas ou sociais e/ou sem justificativas plausíveis para a utilização dessas fórmulas e seu uso é frequentemente legitimado por respostas do tipo "é por definição". A argumentação justificativa, por outro lado, visa à compreensão dos conteúdos, buscando a convicção lógica por parte do aluno. Desta forma, sua utilização no processo de ensino busca apresentar não apenas "como" se faz, mas também, e principalmente, "porque” se faz daquela maneira.

Em termos gerais, podemos dizer que, enquanto a Argumentação Explicativa é utilizada com a finalidade de apenas esclarecer um procedimento, a Argumentação Justificativa tem o objetivo não somente de elucidar, mas de convencer. Em termos discursivos, a um questionamento do aluno sobre o porquê de um procedimento ou fórmula, respostas do tipo "é por definição", "assim dá certo" ou "os matemáticos provaram", são suficientes para uma argumentação explicativa, pois, nesta, só existe a necessidade de mostrar como aquele procedimento ou fórmula funcionam. Já para responder ao questionamento utilizando uma argumentação justificativa, deve ser inevitável a utilização de algum processo que legitime, em termos lógicos, aquele procedimento ou fórmula. Assim, na prática da sala de aula, a argumentação explicativa apresenta o algoritmo de resolução enquanto a argumentação justificativa aponta, além disso, o processo que levou àquele método e que o torna válido. Nossa hipótese é a de que, no processo de ensino de matemática, o modo de argumentação mais utilizado é o primeiro, a argumentação explicativa. Talvez seja desnecessário afirmar, mas reforçamos a ideia em que acreditamos, ou seja, a de que um dos objetivos do ensino de matemática seja a formação de indivíduos críticos e conscientes de seu papel na sociedade e, para que essa meta possa ser atingida, nos parece imperiosa a presença de uma argumentação justificativa.

\section{4- Metodologia Utilizada}

Esta pesquisa pode ser caracterizada como sendo de natureza qualitativa, pois nossa preocupação não esteve em ter uma representação numérica de um fenômeno, 
mas, ao invés disso, em aprofundarmos a compreensão do mesmo. Esse tipo de pesquisa possibilita uma maior flexibilidade quanto aos procedimentos para a coleta dos dados. Para além desse aspecto, a pesquisa teve também um caráter exploratório, pois pretendíamos conseguir uma "maior familiaridade com o problema, com vistas a torná-lo mais explícito ou a constituir hipóteses" (GIL, 2002, p. 41). Podemos dizer que, nesse tipo de pesquisa, o planejamento pode ser flexível, pois permite ponderar sobre certos aspectos pertinentes ao fato investigado. Além disso, a investigação também assumiu um aspecto bibliográfico, pois tivemos como alicerce para fundamentar nossas hipóteses e conclusões a pesquisa em livros e artigos acadêmicos.

Em relação à coleta de dados, realizamos uma análise dos livros didáticos, com o objetivo de apontar semelhanças e diferenças em relação à argumentação utilizada, especialmente em relação à presença ou ausência das categorias de argumentação, e este foi o nosso único eixo de análise. Assim, não consideramos utilizar outras categorias tais como estrutura, organização dos tópicos, nível dos exercícios propostos, articulação entre conteúdos, contextualização, utilização da história, etc. Em relação às categorias de argumentação, nos fundamentamos principalmente em Attie (2016), a partir da conceituação de Balacheff (1988) e quanto à análise destas categorias, consideramos mais apropriado proceder à uma análise de conteúdo (Bardin, 2010), devido ao fato de que os elementos procurados deveriam aparecer explicitados na linguagem de cada objeto (o livro didático).

Como etapas importantes do trabalho, podemos destacar então os seguintes elementos: a investigação sobre os sistemas educacionais nos dois países; a caracterização do nosso eixo de análise; o processo de escolha dos livros didáticos e, por fim, a análise de conteúdo em relação às categorias de argumentação presentes nos livros.

\section{5 - Dados Coletados nos Livros}

\section{1 - Critérios de divisibilidade}

Verificamos dez livros brasileiros ${ }^{7}$ e dois canadenses ${ }^{8}$ e, em todos eles, as regras de divisibilidade aparecem, relativas aos primeiros números naturais (exceto o zero). Entretanto, no caso de quase todos os livros brasileiros, os critérios aparecem, ora 
incompletos, ora sem nenhuma justificação. As deduções desaparecem, e cedem lugar a uma ambicionada indução dos critérios, a partir de poucos exemplos. Em um dos títulos, inclusive, os autores afirmam que a justificativa para os critérios de divisibilidade por 3 e por 9 são um pouco complicadas (com o que discordamos) sendo, portanto, forçoso, que se demonstrem os resultados mais tarde (o que de fato é realizado no livro do último ano desta coleção, mas apenas no nível algébrico). Em outro deles os autores justificam o critério afirmando que "os matemáticos provaram essa regra". Consideramos essa afirmação como apenas mais uma forma de convencer pela autoridade e não pela lógica, "como se as regras passassem a existir a partir de mentes iluminadas, superiores" (ATTIE; MOURA, 2018, p. 06). A única exceção aparece em uma coleção na qual, quando o autor não utiliza o caminho da argumentação justificativa, apresenta atividades exercitando a busca de padrões e regularidades antes da definição do critério.

As duas coleções canadenses abordam o tema de maneira bastante diversa, ainda que bem mais simplificada. Um dos livros apresenta inicialmente vários números divisíveis por 5 e sugere a busca de um padrão para o caso. Faz o mesmo para o 6 e depois disso, sem nenhuma menção a qualquer outro caso, apresenta as regras para os casos 2, 3, 4, 5, 6, 8, 9 e 10 em um quadro específico. Após alguns poucos exercícios explorando a divisibilidade, os autores apresentam o que denominam de um "truque" para a divisibilidade por 7 e pedem que o aluno explique se funciona ou não a partir de exemplos. O caso revela, ao nosso ver, a postura dos autores, de utilizar a indução a partir de poucos exemplos e generalizar os resultados. Repetem-se procedimentos já verificados, em que, a partir de um ou mais exemplos, “o autor já destaca a regra (sem, no entanto, chamar de regra). A partir daí, seguem-se vários exemplos do algoritmo sem mais nenhuma justificação" (ATTIE, 2016, p. 2264). A outra coleção faz uma apresentação interessante para o caso do 3 (e do 9), que podemos chamar de uma argumentação justificativa, pois utiliza uma atividade que, além de mostrar a lógica subjacente ao critério, incentiva a busca do padrão pelos alunos. O livro faz isso apenas nesses dois casos, não apresentando nenhum outro critério para qualquer outro número natural. Ao invés disso, apresenta alternativas de cálculo mental para alguns tipos de divisão e de multiplicação, especialmente por 4 e por 8 . 
Consideramos, por fim que, em todos os casos, seria possível justificar as regras com algumas das mais simples operações aritméticas, como adição, multiplicação e mais a propriedade distributiva.

Apenas para exemplificar como isso poderia ser feito, tomemos o caso da divisibilidade por 3 e vamos ver como, a partir de um caso particular, podemos generalizar o critério para qualquer número natural. Vamos utilizar um número qualquer, por exemplo, 872. Podemos decompor essa quantidade e reescrevê-la de outras formas:

$$
\begin{aligned}
& 872=800+70+2=8 \times 100+7 \times 10+2=8 \times(99+1)+7 \times(9+1)+2= \\
& (8 \times 99+7 \times 9)+(8 \times 1+7 \times 1+2)
\end{aligned}
$$

É fácil ver que o primeiro parêntesis da soma, $(8 \times 99+7 \times 9)$ representa um número divisível por 3, pois 99 e 9 são divisíveis por 3, resultando em uma soma sempre divisível por 3. Logo, para 872 ser um número divisível por 3, basta apenas verificar se o segundo parêntesis, a soma $(8+7+2)$ é divisível por 3. Como deve ser evidente, o processo será o mesmo se houverem mais casas além da centena, pois, nesse caso, qualquer potência de 10 pode ser escrita como $(99 \ldots 99+1)$, com essa quantidade de noves variando de acordo com o expoente. Consideramos que uma introdução ao assunto com um número menor (da ordem das dezenas, por exemplo), pode ser uma maneira de justificar esse critério de divisibilidade em um livro didático.

Ainda que as demonstrações possam ser feitas de outra maneira, utilizando-se de congruências, por exemplo, consideramos que não seria recomendável em termos didáticos, visto que é um assunto de nível universitário. Mesmo o uso da álgebra do final do Ensino Fundamental seria uma antecipação ao tratar do assunto.

\section{2 - Expressões numéricas}

Este conteúdo, da mesma forma que o anterior, é ensinado atualmente nos primeiros anos tanto do Ensino Fundamental II, no Brasil, como da Elementary School, no Canadá. Verificamos, dentro desse assunto, que tipo de argumentos os vários autores utilizavam para justificar por exemplo, por que, em uma expressão numérica, a multiplicação deve ser feita antes da adição. O simples fato de que a multiplicação é uma adição de parcelas repetidas, que poderia ser utilizado para a justificativa, não aparece em nenhum dos livros 
analisados (cinco coleções brasileiras e duas canadenses). Em todos elas, ao contrário, são apresentadas regras e truques mnemônicos para que o aluno memorize, ao que parece, sem saber porque funciona daquele jeito.

Nos livros brasileiros, os autores apenas definem a prioridade das operações e apresentam exemplos e exercícios. As tentativas de contextualização e de um desenho gráfico atraente são louváveis, mas não conseguem esconder o fato de que não aparece sequer um argumento mostrando porque as operações devem ser feitas na ordem apresentada. Em todos os livros brasileiros, a prioridade na resolução entre os símbolos (parêntesis, colchetes e chaves) também é apresentada como uma regra convencionada.

Nas coleções canadenses, da mesma forma, as regras aparecem e nada mais. Nenhuma menção ao porquê das prioridades. Um dos livros ainda apresenta uma regra mnemônica que supostamente, ajudará o aluno a memorizar a ordem das operações e símbolos. Para não dizermos que não há incentivo ao raciocínio, esta coleção questiona o fato de haverem seis letras no truque mnemônico utilizado e apenas quatro passos na regra.

Assim, em 100\% dos casos, os livros "afirmam simplesmente que esse é o procedimento e apresentam exemplos de como é feito" (Attie, 2016, p. 2263). Consideramos que a totalidade dos autores, neste caso específico, perdem uma grande chance de apresentar a lógica subjacente aos fatos matemáticos. Uma pequena introdução ao tema mostrando que qualquer multiplicação pode ser transformada em adição (mas não o contrário) poderia justificar a prioridade entre essas duas operações. No caso particular dos parêntesis, colchetes e chaves, concordamos com a apresentação da prioridade como uma convenção.

Apenas ressalvamos o fato de que poderia ser mostrada a necessidade dessa priorização de símbolos para a organização de uma expressão.

\section{$\underline{3 \text { - Divisão de frações }}$}

As duas coleções canadenses analisadas apresentam pelo menos dois tipos de resolução para uma divisão entre frações. Em ambos os casos, aparece a ideia de que, em uma divisão, precisamos descobrir “quantos cabem”. Além disso, apresentam uma 
argumentação, que consideramos justificativa, em que utilizam uma transformação para um denominador comum entre as frações para que a ideia de "quantos cabem" seja compreensível. Em um dos exemplos, ao questionar quantos 2/5 cabem em 1/3, os autores transformam as frações para o mesmo denominador e se perguntam agora quantos 6/15 cabem em 5/15, o que, enfim, faz algum sentido. O outro tipo de argumentação, que consideramos explicativa, apresenta o fato de que dividir por uma fração é o mesmo que multiplicar pelo seu inverso.

No caso das coleções brasileiras, dos seis livros analisados, apenas um apresenta uma argumentação justificativa, que consideramos, inclusive, trazer uma valorização do aspecto lógico à questão. Ao considerar a divisão $2 / 3: 5 / 7$ e se perguntar quantos $5 / 7$ cabem em $2 / 3$, os autores consideram multiplicar ambas as frações pelo número 1 (o que não altera o seu resultado), e escolhem um caso particular desse número, fazendo $1=7 / 5: 7 / 5$. Assim, a conta fica $(2 / 3 \times 7 / 5):(5 / 7 \times 7 / 5)$, o que resulta em $(5 / 7$ x 7/5):1, transformando um problema inicial, que não conseguíamos resolver, em uma operação que já conhecemos. Enquanto isso, os outros cinco livros, apesar de também apresentarem a ideia de "quantos cabem" para ilustrar o conceito, trazem a regra para a resolução sem nenhuma justificativa, revelando assim "exigências de adestramento, repetição e disciplinamento, entendidas na escola como condição de sucesso em Matemática" (SANTOS, 1989, p. 03).

Ainda que, proporcionalmente tenhamos mais presença de argumentos justificativos nos livros canadenses (100\%) do que nas coleções brasileiras $(17 \%)^{9}$, gostaríamos de sugerir neste artigo a utilização dos dois tipos de argumentações justificativas, ambas fortes, e complementares, ao nosso ver, para a compreensão da questão.

\section{4 - Operações com inteiros}

Dentro deste tema, optamos por analisar a multiplicação entre números negativos, por considerarmos que é uma parte do assunto em que os argumentos justificativos são mais necessários.

Entre as duas coleções canadenses, apesar das abordagens diferentes, pudemos perceber a busca de uma argumentação justificativa em ambas. Um dos livros utiliza, 
em três exemplos, um sentido para a distância e uma velocidade associada e, em dois deles, conduz o estudante ao resultado de que o produto de dois negativos é positivo. Em seguida, os autores exploram a busca de padrões e sequências de números para mostrar o resultado. Por fim, apresentam as regras para o produto de inteiros. No outro livro, os autores utilizam as propriedades comutativa, distributiva e um postulado de Aristóteles para demonstrar que o produto de dois negativos é positivo. A partir daí, apresentam as regras (produto de sinais iguais $\rightarrow$ positivo; produto de sinais diferentes $\rightarrow$ negativo).

Nas coleções brasileiras analisadas o quadro foi bastante diverso pois, no caso do produto entre inteiros negativos, de cinco livros, três apresentam as regras a partir de uma busca de padrões, utilizando sequências de números. As outras duas obras apenas apontam as "regras" para o produto, logo depois dos exemplos, caracterizando um processo de argumentação explicativa, em que se convence o aluno de como fazer e não por que fazer daquela maneira. Apesar da primeira abordagem ser mais promissora, ainda não pode ser considerada satisfatória, pois, naqueles casos "as deduções desaparecem, e cedem lugar a uma ambicionada indução dos critérios, a partir de poucos exemplos" (ATTIE, 2013, p. 40).

De fato, uma indução a partir de sequências, ou a utilização da reta numerada, com distâncias e sentido associados ou uma demonstração a partir das propriedades das operações podem ser consideradas alternativas válidas e, em alguns casos, até mesmo como uma argumentação justificativa. Ao nosso ver, entretanto, certos procedimentos, mesmo não sendo puramente matemáticos, são mais desejáveis do ponto de vista didático, por apresentarem maior possibilidade de aprendizagem, tanto pela contextualização envolvida, quanto por sua abordagem, que utiliza menos a linguagem simbólica que a linguagem natural, como os exemplos que sugerimos em seguida ${ }^{10}$. O primeiro enfoque aparece tanto em livros canadenses como brasileiros. Já a segunda abordagem citada, por exemplo, que aparece apenas em uma coleção canadense, se mais aprofundada e enriquecida com outros elementos, seria a alternativa que consideramos mais apropriada, e que sugerimos aqui. Considerar sentidos positivos para a distância, associados com o tempo e a velocidade, poderiam ensejar questões do tipo "há 3 horas, em que posição estava uma pessoa que caminhou a -5 metros por segundo (ou seja, a $5 \mathrm{~m} / \mathrm{s}$ em sentido 
negativo)?”. Utilizar a vazão de um líquido em um recipiente e, novamente, o tempo a velocidade, renderiam um questionamento como "há cinco minutos, qual era o volume do recipiente, se ele vaza 4 litros por minuto?". Acreditamos que questões como estas, ainda que não puramente matemáticas, associadas ao produto de inteiros (e acrescidas de outras abordagens) podem auxiliar a aprendizagem no sentido de apresentar ao estudante mais uma argumentação justificativa para o fato de que o produto de negativos dá positivo.

\section{5- Áreas}

Este assunto é abordado, em geral, tanto do Ensino Fundamental II, no Brasil, como da Elementary School, no Canadá. As fórmulas e demonstrações, entretanto, são apresentadas, no Brasil, nos anos finais desses níveis, enquanto que no Canadá, distribuídas ao longo dos anos. Verificamos quatro coleções brasileiras e duas canadenses. Em todos os casos, as áreas são deduzidas a partir de decomposições e recomposições geométricas e a partir da definição da área do quadrado (que não é justificada).

Como iremos apontar, as provas apresentadas pelas coleções podem ser caracterizadas como provas intelectuais (Balacheff, 1988). Os livros, em geral, deduzem a área de paralelogramo, a partir da decomposição e recomposição de partes, transformando o paralelogramo em retângulo, e também do triângulo, considerando dois triângulos congruentes e transformando a junção em um paralelogramo. Da mesma forma, a área do trapézio é encontrada ao juntar dois trapézios congruentes e formar assim um paralelogramo. A área do losango, que não aparece em uma coleção brasileira, é deduzida a partir de um retângulo circunscrito a ele, e que é formado por 8 triângulos retângulos, dos quais metade forma o losango. No caso do círculo, os autores canadenses (das duas coleções) e alguns dos autores brasileiros recorrem a uma aproximação do mesmo, dividido em fatias congruentes e, recompondo de maneira adequada, chegam a uma figura parecida com um paralelogramo e, a partir daí, chegam à área do círculo. Um dos livros brasileiros, entretanto, utiliza, incorretamente, a expressão "partes iguais", quando quer dizer "partes congruentes". Consideramos que, no caso desta última coleção, o fato de as fórmulas aparecerem antes das deduções pode comprometer o processo de aprendizagem. Outra coleção brasileira recorre à aproximação do círculo com polígonos 
com um número cada vez maior de lados (sem ao menos citar Arquimedes), e, ao fim, apresenta a fórmula da área. É, ao nosso ver, além do fato de que a área do quadrado é apresentada "por definição", o único deslize em relação à presença de uma argumentação explicativa dentro do assunto, pois todos os livros analisados fazem uso de argumentação justificativa para o tema.

\section{Considerações Finais}

As opções feitas nesta pesquisa, especialmente em relação à escolha de conteúdos a serem analisados, foram propositais, por considerarmos que são casos em que as justificativas por vezes não aparecem explicitamente. Sabemos que existem demonstrações para cada um dos casos estudados, e a maior parte das justificativas pode ser elaborada em nível compatível à compreensão de alunos do Ensino Fundamental e que, portanto, poderiam estar presentes nos livros didáticos deste nível. Entretanto, ao não apresentar argumentação desse tipo, é negada ao estudante a possibilidade de compreensão do processo que justifica esse conhecimento, em privilégio de uma espécie de adestramento das regras e da memorização, sendo que "uma das mais trágicas decorrências desse cenário seria a carência de argumentações (lógica e didaticamente) válidas no processo de ensino e aprendizagem da disciplina" (ATTIE, 2013, p.12).

Nossa ponderação é a de que, em relação ao tipo de abordagem implementada nos livros didáticos, o ensino de matemática no Canadá encontra-se em um padrão superior ao do Brasil, em vista do uso mais frequente da busca de padrões e regularidades e do incentivo ao raciocínio, que permeia quase todos os assuntos das coleções.

Entretanto, em uma análise mais acurada, podemos apontar a surpreendente falta dessa abordagem na argumentação de alguns assuntos (critérios de divisibilidade e expressões numéricas, por exemplo). É como se ainda fosse necessário realizar uma "sintonia fina", para ajustar o enfoque geral, que consideramos acertado (a busca de padrões e regularidades e o incentivo ao raciocínio) com os elementos particulares (pois ainda aparecem assuntos sem nenhuma justificativa, com apenas regras mnemônicas para a memorização). Com este artigo e suas sugestões, esperamos auxiliar especialmente nesse processo de ajuste, que consideramos necessário. 


\section{Referências}

JATTIE, João Paulo. Relações de poder no processo de ensino e aprendizagem de matemática. Tese (Doutorado em Educação). Faculdade de Educação da Universidade de São Paulo, São Paulo, 2013.

Argumentação no ensino de matemática. In: III Seminário Internacional de Estudos sobre Discurso e Argumentação (SEDiAr), 3, 2016, São Cristóvão. Anais: Ilhéus. EDITUS, 2016. p. 2259-2268. http://www.uesc.br/cursos/graduacao/licenciatura/letras/ proeda/arquivos/anais_iiisediar_2016.pdf

ATTIE, J. P.; MOURA, M. O. A altivez da ignorância matemática: Superbia Ignorantiam Mathematicae. Educação e Pesquisa, v. 44, e152362, 2018. https://doi.org/10.1590/ s1517-9702201702152362

BALACHEFF, Nicholas. Une étude des processus de preuve en mathématique chez des élèves de Collège. Thèse d'état. Université Joseph Fourier, Grenoble, France, 1988. http:// hal.univ-grenoble-alpes.fr/tel-00326426/

BARBOSA, E. P. Os por quês matemáticos dos alunos na formação dos professores. In: XIII Conferência Interamericana de Educação Matemática (CIAEM), 13, 2011, Recife. Anais: Recife, 2011. https:/xiii.ciaem-redumate.org/index.php/xiii_ciaem/xiii_ciaem/ paper/viewFile/611/770

BARDIN, Laurence. Análise de conteúdo. Lisboa: Edições 70, 2010.

BRASIL, Ministério da Educação e Cultura, Secretaria de Educação Básica. Guia do Plano Nacional do Livro Didático, Ensino Fundamental, Anos Iniciais, Alfabetização Matemática e Matemática. ISBN 978-85-7783-195-1. Brasília, 2015.

, Ministério da Educação e Cultura, Secretaria de Educação Básica. Guia do Plano Nacional do Livro Didático, Ensino Fundamental II, Matemática. ISBN 978-857783-226-2. Brasília, 2016.

CANADA. Alberta Education. Western and Northern Canadian Protocol. ISBN 978-1-4601-2398-0. Alberta, Canadá, 2015. https:/education.alberta.ca/ media/481798/2015_k-9_math_ach_ind_phase_1.pdf

CARVALHO, Leane Oliveira; SANTOS, Thamires Ferreira; ATTIE, João Paulo. Processos de argumentação no ensino fundamental: frações e potências. In: XII Encontro Nacional de Educação Matemática (ENEM), 12, 2016, São Paulo. Anais: São Paulo: SBEM, 2016. http://www.sbembrasil.org.br/enem2016/anais/pdf/6199_3504_ID.pdf

CRUZ, E. S.; ATTIE, J. P; SANTOS, T. M. Processos argumentativos presentes nos conteúdos de análise combinatória em livros didáticos do ensino médio. In: XII Colóquio Internacional Educação e Contemporaneidade (EDUCON), 12, 2018, São Cristóvão. Anais: São Cristóvão: EDUFS, 2018. http://anais.educonse.com.br/2017/processos argumentativos_presentes_nos_conteudos_de_analise_combi.pdf

GIL, Antonio Carlos. Como elaborar projetos de pesquisas. São Paulo: Atlas, 2002. 
LIMA, M.; ANDRADE, R. S. J.; LIMA, M. G. B. Realidade Educacional do Brasil e do Canadá: Pistas a partir dos resultados em leitura do PISA. In: VI Colóquio Internacional Educação e Contemporaneidade (EDUCON), 6, 2012, São Cristóvão. Anais: São Cristóvão: EDUFS, 2012 http://educonse.com.br/2012/eixo_12/PDF/40.pdf

LORENZATO, S. Os "por quês" matemáticos dos alunos e as respostas dos professores. Pro-posições, vol 4, n. 1(10), 1993. https://www.fe.unicamp.br/pf-fe/publicacao/1760/10artigos-lorenzatos.pdf

NASCIMENTO, E. S.; MATUCELI, M.; COSTA, M. B. L. Argumentação em livros didáticos: Equações do $1^{\circ}$. Grau. In: XIII Colóquio Internacional Educação e Contemporaneidade (EDUCON), 13, 2019, São Cristóvão. Anais: São Cristóvão: EDUFS, 2019. https://ri.ufs.br/bitstream/riufs/13178/21/20.pdf

OCDE (Organização para a Cooperação e o Desenvolvimento Econômico). Reform to Support High Achievement in a Diverse Context. OECD Publishing, Ontario, Canada, 2010. https://www.oecd.org/pisa/pisaproducts/46580959.pdf

SALES, A.; PAIS, L. C. A argumentação em matemática no guia de livros didáticos. In: XII Encontro Brasileiro de Pesquisa em Educação Matemática (EBRAPEM), 12, 2008, Rio Claro. Anais: Rio Claro, Unesp, 2008. http://www2.rc.unesp.br/eventos/matematica/ ebrapem2008/upload/106-1-A-gt11_sales_ta.pdf

SANTOS, Tamara Melo; ATTIE, João Paulo; CRUZ, Elvis dos Santos. Argumentação no ensino de trigonometria em livros didáticos. In: XII Colóquio Internacional Educação e Contemporaneidade (EDUCON), 12, 2018, São Cristóvão. Anais: São Cristóvão: EDUFS, 2018. https://ri.ufs.br/bitstream/riufs/9017/70/Argumentacao_no_ensino_de_ trigonometria_em_livros_didaticos.pdf

SANTOS, Vinício Macedo. A Matemática no $1^{\circ}$ grau: O Significado que Pais, Alunos e Professores Conferem à Matemática. Dissertação (Mestrado em Educação). Faculdade de Ciências Exatas e Tecnologia, Pontifícia Universidade Católica, São Paulo, 1989.

SCHEFFER, N. F. A argumentação em matemática na interação com tecnologias. Ciência e Natura, vol 34(1), pp. 23-28, 2012. https://periodicos.ufsm.br/cienciaenatura/article/ viewFile/9352/5503

SOARES, L. H.; OLIVEIRA, W. S. Os por quês matemáticos na prática docente: importância, concepção e conhecimento do professor. Principia, vol 44, pp. 100-112. https://periodicos.ifpb.edu.br/index.php/principia/article/view/1936

SOUZA, L. C. Livros Didáticos de Matemática do Brasil e Canadá: um enfoque em construção geométrica nos anos finais do ensino fundamental. Dissertação (Mestrado em Ciências). Instituto de Matemática e Estatística. Universidade de São Paulo, São Paulo, 2019.https:/www.teses.usp.br/teses/disponiveis/45/45135/tde-27062019-200308/ publico/Dissertacao_Leonardo_Cascio.pdf

ANDRINI, Alvaro; VASCONCELLOS, Maria José. Praticando matemática. $6^{\circ}$ ano. São Paulo: Editora do Brasil, 2015. 
BIANCHINI, Edwaldo. Matemática. $8^{\circ}$ ano. São Paulo: Moderna, 2014.

BIGODE, Antonio José Lopes. Matemática do Cotidiano. $6^{\circ}$ ano. São Paulo: Scipione, 2015.

CENTURIÓN, Marília; JAKUBOVIC, José. Matemática nos dias de hoje. $6^{\circ}$ ano. São Paulo: Leya, 2015.

CENTURIÓN, Marília; LA SCALA, Junia; RODRIGUES, Arnaldo. Porta Aberta. $5^{\circ}$ ano. São Paulo: FTD, 2014.

CHAVANTE, Eduardo. Convergências: matemática. $6^{\circ}$ ano. São Paulo: SM, 2015.

DANTE, Luis Roberto. Projeto Teláris, Matemática. $6^{\circ}$ ano. São Paulo: Ática, 2014.

. Projeto Teláris, Matemática. $9^{\circ}$ ano. São Paulo: Ática, 2015.

GAY, Marcia Regina Garcia. Projeto Araribá: Matemática. $6^{\circ}$ ano. São Paulo: Moderna, 2014.

GIOVANNI JÚNIOR, José Rui. A Conquista da Matemática. $5^{\circ}$ ano. São Paulo: FTD, 2015.

. A Conquista da Matemática. $9^{\circ}$ ano. São Paulo: FTD, 2014.

MAZZIEIRO, Alceu dos Santos; MACHADO, Paulo Antonio Fonseca. Descobrindo e Aplicando a Matemática. $6^{\circ}$ ano. Belo Horizonte: Dimensão, 2015.

MORI, Iracema; ONAGA, Dulce Satiko. Matemática: Ideias e Desafios. $6^{\circ}$ ano. São Paulo: Saraiva, 2012.

ONTARIO. Guidelines for Approval of Textbooks. Ontario, 2008.

SILVEIRA, Enio. Matemática: Compreensão e Prática. $6^{\circ}$ ano. São Paulo: Moderna, 2015.

. Projeto Navegar. Matemática. $5^{\circ}$ ano. São Paulo: Moderna, 2014.

SMOLE, Katia Stocco; MARIM, Vlademir; DINIZ, Maria Ignês. Saber Matemática. $5^{\circ}$ ano. São Paulo: FTD, 2014.

SOUZA, Joamir; PATARO, Patrícia Moreno. Vontade de saber, Matemática. $6^{\circ}$ ano. São Paulo: FTD, 2014.

. Patrícia Moreno. Vontade de saber, Matemática. $9^{\circ}$ ano. São Paulo: FTD, 2015.

TABOADA, Roberta; LEITE, Angela. Aprender Juntos. Matemática. $5^{\circ}$ ano. São Paulo: SM, 2014.

BURNETT, Claire et al. Math Makes Sense Six. Canada: Pearson Education, 2006.

. Math Makes Sense Seven. Canada: Pearson Education, 2005.

. Math Makes Sense Eight. Canada: Pearson Education, 2008. 
KESTELL, Mary Lou; SMALL, Marian et al. Nelson Mathematics Six. Toronto: Thomson, 2006.

SMALL, Marian et al. Nelson Mathematics Seven. Toronto: Thomson, 2005. Nelson Mathematics Eight. Toronto: Thomson, 2007.

\section{Notas}

1 Professor Doutor em Educação, Universidade Federal de Sergipe. Professor Associado do Departamento de Matemática (DMA-UFS), São Cristóvão, Sergipe, Brasil. jpattie@mat.ufs.br. Este artigo apresenta os resultados de uma pesquisa colaborativa, conduzida pelo pesquisador e orientada pela profa. Cathy Marks Krpan, aqui, co-autora do artigo.

2 Professora Doutora em Educação, University of Toronto. Professora Associada do Ontario Institute for Studies in Education (OISE-UofT), Toronto, Ontario, Canada. cathy.marks.krpan@utoronto.ca.

3 A OCDE tem por objetivo promover políticas que visem o desenvolvimento econômico e o bem-estar social de pessoas por todo o mundo É uma organização internacional, criada em 1961, composta por 34 países e com sede em Paris, França.

4 Por estarem entre as dúvidas mais frequentes apresentadas pelos alunos (Lorenzato, 1993; Barbosa, 2011; Soares e Oliveira, 2019).

5 Recomendados no Guia de Livros Didáticos PNLD 2016. Ensino Fundamental. Anos Iniciais: Alfabetização Matemática e Matemática (BRASIL, 2015) e/ou no Guia de Livros Didáticos PNLD 2017. Ensino Fundamental. Anos Finais: Matemática (BRASIL, 2016).

6 "Os conselhos escolares podem selecionar livros didáticos da Lista Trillium e aprová-los para uso em suas escolas" (ONTARIO, 2008, p.1).

7 Do $5^{\circ}$ ano: Centurión et al (2008), Giovanni Jr (2015), Silveira (2014), Smole et al (2014) e Taboada et al (2014). E do 6o ano: Andrini et al (2015), Bigode (2000), Chavante (2015), Dante (2014) e Gay (2014).

8 Burnett et al (2006) e Kestell et al (2006).

9 Já que essa categoria se encontra em todas as coleções canadenses e em apenas uma das seis coleções brasileiras.

10 Apenas para que o leitor tenha uma ideia de como seria uma prova matemática, apresentamos a demonstração do matemático Colin MacLaurin, que viveu no século XIX: Como a - a =0, se multiplicarmos qualquer valor na igualdade, o resultado continuará sendo 0 . Assim, se multiplicarmos o valor $(-\mathrm{n})$, teremos $(-\mathrm{n})$.(a $-\mathrm{a})=0$, e daí, $(-\mathrm{n}) \cdot(\mathrm{a})+(-\mathrm{n})(-\mathrm{a})=0$, e, se $(-\mathrm{na})+(-\mathrm{n})(-\mathrm{a})=0$, o único valor possível para $(-\mathrm{n})(-\mathrm{a})$ será o de (n.a). 